\title{
A PROPOSAL FOR A DISTINCTION IN BELIEF FUNCTIONS I
}

\author{
Mehmet Nebioğlu ${ }^{1, *}$, Tarık Çakar ${ }^{2}$ and Raşit Köker ${ }^{3}$ \\ ${ }^{1}$ Department of Logistics of Vocational School, Gediz University \\ Seyrek, Menemen, Izmir, Turkey \\ ${ }^{2}$ Department of Industrial Engineering, Sakarya University, Esentepe, Sakarya, Turkey \\ ${ }^{3}$ Department of Computer Engineering, Sakarya University, Esentepe, Sakarya, Turkey \\ mehmetnebioglu11@yahoo.com, tcakar@sakarya.edu.tr, rkoker@sakarya.edu.tr
}

\begin{abstract}
This study proposes a distinction between the belief function and the credibility function in mind design - a section of artificial intelligence. We show the distinction between the credibility and belief measures first. Then we evaluate the possibility of these measures in case studies and consider the credibility and belief values of each case. This is a novel method for the evaluation of belief functions and it is shown that they satisfy the rules of current belief function axioms.
\end{abstract}

Key Words- Belief measure, belief functions, credibility measure, Dempster - Shafer belief functions

\section{INTRODUCTION}

Dempster-Shafer theory is put forward to cover several models that use the mathematical object called 'belief function' by Shafer [1]. The aim of his study was the modeling of someone's degrees of belief. The Dempster-Shafer theory is a generalization of the Bayesian theory of individual probability. The Bayesian theory requires probabilities for each question of interest; on the other hand, belief functions allow us to base degree of belief for one question on probabilities for a related question, and this is called power set. These degrees of belief may or may not have the mathematical properties of probabilities; how much they differ from probabilities will depend on how closely the two questions are related.

\subsection{Shafer's Theory of Evidence}

Belief functions are defined as follows by Shafer [1]. If $\Theta$ is a frame of discernment, then a function $\mathrm{Bel}: 2^{\Theta} \rightarrow[0,1]$ is a belief function if and only if it satisfies following conditions:

$$
\begin{aligned}
& 1-\operatorname{Bel}(\varnothing)=0 \\
& 2-\operatorname{Bel}(\Theta)=1
\end{aligned}
$$

3 - For every positive integer $n$ and every collection $A_{1}, A_{2} \ldots A_{n}$ of subsets of $\Theta$ 
$\operatorname{Bel}\left(\mathrm{A}_{1} \mathrm{UA}_{2} \mathrm{U} \ldots \mathrm{U} \mathrm{A}_{\mathrm{n}}\right) \geq \sum_{I \subset\{1, \ldots, n\}}(-1)^{|I|+1} \operatorname{Bel}\left(\cap_{i \in I} A_{i}\right)$

Belief functions are also called Credibility functions by many researchers. Associated with each belief measure, there is a Plausibility measure ' $\mathrm{Pl}$ ' and it is defined by the equation [2]

$\operatorname{Pl}(\mathrm{A})=1-\operatorname{Bel}(\hat{\mathrm{A}})$

or in the same way [3]

$\operatorname{Pl}(\mathrm{A})=1-\operatorname{Cr}(\hat{\mathrm{A}})$

Degree of doubt on an evidence $\mathrm{A}$ is shown by $\operatorname{Dou}(\mathrm{A})=\operatorname{Bel}(\hat{\mathrm{A}})$

Therefore we can say $\mathrm{Pl}(\mathrm{A})=1-\operatorname{Dou}(\mathrm{A})$

The following remarks are made with respect to Plausibility measure [1]:

1) $\mathrm{Pl}(\mathrm{A})$ measures the degree to which one fails to doubt $\mathrm{A}$, where $\operatorname{Dou}(\mathrm{A})=\operatorname{Bel}(\hat{\mathrm{A}})$

2) $\mathrm{Pl}(\mathrm{A})$ measures the total belief mass that can be allocated into $\mathrm{A}$, whereas $\mathrm{Bel}(\mathrm{A})$ measures the total belief mass that is allocated to $\mathrm{A}$.

3) $\mathrm{Pl}(\mathrm{A})=\sum_{A_{i} \cap A \neq \varnothing} m\left(A_{i}\right)$

4) $\operatorname{Bel}(\mathrm{A}) \leq \operatorname{Pl}(\mathrm{A})$

From the super additively property of belief functions above, it is easy to say [2]

$$
\begin{array}{r}
\left.\mathrm{Pl}\left(\mathrm{A}_{1} \mathrm{UA}_{2} \mathrm{U} \ldots . \mathrm{U} \mathrm{A}_{\mathrm{n}}\right) \leq \sum_{i}[P l(A)]_{i}\right]-\sum_{i<j}\left[P l\left(A_{i} \cap A_{j}\right)\right]+\ldots . . \\
+(-1)^{\mathrm{n}+1} \quad P l\left(A_{1} \cap A_{2} \cap . . A_{n}\right)
\end{array}
$$

$\operatorname{Bel}(\mathrm{A})+\operatorname{Bel}(\hat{\mathrm{A}}) \leq 1$ and $\quad \operatorname{Pl}(\mathrm{A})+\operatorname{Pl}(\hat{\mathrm{A}}) \geq 1$

Belief functions are generally obtained by support functions. The relation between support functions and belief functions[1] are given in Figure 1.

$$
\left\{\begin{array}{l}
\text { Simple } \\
\text { Support } \\
\text { Func }
\end{array}\right\} \subseteq\left\{\begin{array}{l}
\text { separable } \\
\text { support } \\
\text { func }
\end{array}\right\} \subseteq\left\{\begin{array}{l}
\text { support } \\
\text { func }
\end{array}\right\} \subseteq\left\{\begin{array}{l}
\text { belief } \\
\text { func }
\end{array}\right\}
$$

Figure 1. A general view of belief functions 


\section{THE PROPOSED METHOD}

In the proposed method, some of the formulations are put forth in a heuristic way. How we think or how we believe is an innate knowledge. Here, we only try to get a formulation of this knowledge and to reveal why it is tackled in such a way.

One can say that belief is much stronger then credibility from the daily use of these words. Belief means allocating your faith to one option and rejecting the other options; whereas, credibility means trustworthiness. Therefore, it is possible to make a distinction between these two words. Credibility functions can be thought as pre-belief functions and is a priori for constructing our belief. Usual belief functions can be called as credibility functions.

$$
\begin{aligned}
& \operatorname{Cr}(\mathrm{A})=1-\operatorname{Pl}(\hat{A}) \\
& \operatorname{Pl}(\mathrm{A})=1-\operatorname{Cr}(\hat{A}) \\
& \operatorname{Dou}(\mathrm{A})=1-\operatorname{Cr}(\mathrm{A}) \\
& \operatorname{Pl}(\mathrm{A})=\operatorname{Dou}(\hat{A})
\end{aligned}
$$

\subsection{Explanation}

Belief functions must be much stronger than credibility functions[4]. Besides the vocabulary meaning, in our daily life we sometimes say that we don't believe an idea just by evaluating 'how plausible the ideas', but we also look for 'how plausible complement of this idea'. In other words, we don't believe an idea just by evaluating only 'how credible the ideas', but we also look for 'how credible is the complement of this idea'. Different ideas about an event are the antithesis of each other. Each idea's credibility is only as valuable as the other thesis left us to take into account it.

For example, assume there are two ideas about a subject. One of them is highly credible (or plausible) and the other is not. In this case, we take the first idea into account much more. But if both of the ideas are highly credible (or plausible) we won't be so bold to take the first idea into account. This consideration shows us that each idea is as valuable as its credibility and remaining value of its complement's credibility.

Table 1. Basic allocations of belief by two possible results (A and B) game [4]

\begin{tabular}{|c|c|c|}
\hline & $\mathrm{A}$ & $\overline{\mathrm{A}}$ \\
\hline $\mathrm{B}$ & 1 & 2 \\
\hline$\overline{\mathrm{B}}$ & 3 & 4 \\
\hline
\end{tabular}

As another example, let us consider an experiment with only two possible results in a Bayesian space (head or toss experiment). Assume some degree of credibility is allocated to these two possible results by some support functions. In such circumstances we have four divisions in mind to evaluate this situation and there are certain values for these divisions. These four divisions are represented in Table 1 where division 1 means that both A and B seem to occur. In a Bayesian space it is not possible for both of them to occur simultaneously and it is obvious that this part of division means hesitation. 
Similarly division 4 means that both A and B seem not to occur, yet one of them must occur. This division also represents hesitation. Under these conditions belief in A is represented by division 3 in which trusts in A to occur and trust in B not to occur. In a similar way belief in $\mathrm{B}$ is represented by division 2 .

\subsection{Approach by an Electronic View}

From another point of view, we can think this problem like a xor gate [4]. In a xor gate, the result is true (or equal to one) if and only if $\mathrm{A}$ is not equal to $\mathrm{B}$. Gate works such that; if both A and B are equal to one, currents blockade each other. So there will be no output (each output will be equal to zero). If A and B are both equal to zero, then there is no blockade but also there is no output current (means outputs are zero). If one of the inputs (e.g. A) is 1 , then the other one (B) is zero current. 'A' won't be blockaded and output of $\mathrm{A}$ is one.

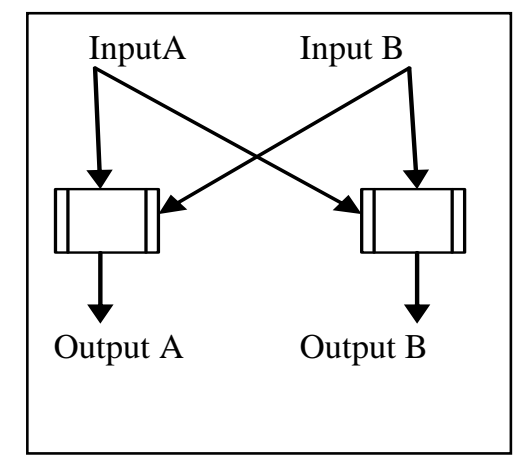

Figure 2.Basic electronic model of belief by two possible results (A and B) game [4]

This output can be modeled as

Output $(A)=A^{*}(1-B)$

Output $(\mathrm{B})=\mathrm{B}^{*}(1-\mathrm{A})$

In a similar way allocating belief problem can be thought as a xor problem. This is because each idea is the antithesis of the other.

\subsection{Formulation of the Proposed System}

According to all propositions above for a frame of discernment $\Theta$, proposed belief function in the set of $2^{\Theta}$ is [5]

A: Every items of power set $2^{\Theta}$ except A

such that $\mathrm{A} U \overline{\mathrm{A}}=2^{\Theta}$ 
$\hat{A}$ : Every items of power set $2^{\Theta}$ which has no intersection with $\mathrm{A}(\mathrm{A} \cap \hat{\mathrm{A}}=\varnothing)$.

$$
\begin{aligned}
& \operatorname{Bel}(\mathrm{A})=\operatorname{Pl}(\mathrm{A}) *[1-\operatorname{Pl}(\hat{\mathrm{A}})] \\
& \operatorname{Bel}(\mathrm{A})=\left[\sum_{A_{i} \cap A \neq \varnothing}\left[m\left(A_{i}\right)\right]\right] *\left[1-\sum_{A_{i} \subset \bar{A}}\left[m\left(A_{i}\right)\right]\right] \\
& \operatorname{Bel}(\mathrm{A})=\operatorname{Pl}(\mathrm{A}) *[1-\operatorname{Dou}(\mathrm{A})] \\
& \operatorname{Bel}(\mathrm{A})=\operatorname{Pl}(\mathrm{A}) * \operatorname{Cr}(\mathrm{A}) \\
& \operatorname{Bel}(\mathrm{A})=[1-\operatorname{Cr}(\hat{\mathrm{A}})] * \operatorname{Cr}(\mathrm{A}) \\
& \operatorname{Bel}(\mathrm{A})=\left[1-\sum_{A_{i} \subset \hat{A}}\left[m\left(A_{i}\right)\right] *\left[1-\sum_{A_{i} \subset A}\left[m\left(A_{i}\right)\right]\right]\right.
\end{aligned}
$$

In equation(13), belief measurement is obtained with plausibility of an option which is weighted with plausibility of the complement of this option. In equation(14), the terms are replaced with their expressed formulas with basic assignments. In equation(15), we can replace $\mathrm{Pl}(\hat{\mathrm{A}})$ with Dou(A) resulting of plausibility weighted with doubt of this option as $[1-\operatorname{Dou}(\mathrm{A})]$.

Furthermore we can obtain for $\mathrm{a}_{\mathrm{i}} \subset \mathrm{A}$

$\operatorname{Bel}(\mathrm{A})=\sum_{a_{i} \subset A} C_{r}\left(a_{i}\right) \cdot P l\left(a_{i}\right)$

That $0<\mathrm{Cr}(\mathrm{A})<1 \quad$ and $\quad 0<\mathrm{Pl}(\mathrm{A})<1$ we can obtain

$\operatorname{Bel}(\mathrm{A}) \leq \operatorname{Cr}(\mathrm{A}) \leq \operatorname{Pl}(\mathrm{A})$

Such a definition helps us to understand why Bel $\left(\mathrm{A}_{1} \mathrm{UA}_{2} \mathrm{U} \ldots . \mathrm{UA}_{\mathrm{n}}\right)$ is bigger or equal to $\sum_{i}\left[\operatorname{Bel}(A)_{i}\right]-\sum_{i<j}\left[\operatorname{Bel}\left(A_{i} \cap A_{j}\right)\right]+\ldots \ldots+\quad(-1)^{\mathrm{n}+1} \operatorname{Bel}\left(A_{1} \cap A_{2} \cap . . \cap A_{n}\right)$. According to such a formulation it is obvious that even if the credibility function is linear belief function will not be linear.

\section{THE FORM OF BELIEF FUNCTION SATISFYING THE DEMPSTER- SHAFER BELIEF FUNCTION AXIOMS}

If $\Theta$ is a frame of discernment, Dempster-Shafer [1] belief function axioms on power set of $\Theta$ are

$$
\begin{aligned}
& \operatorname{Bel}: 2^{\Theta} \rightarrow[0,1] \\
& 1-\operatorname{Bel}(\varnothing)=0 \\
& 2-\operatorname{Bel}(\Theta) \leq 1
\end{aligned}
$$




$$
\begin{gathered}
3-\operatorname{Bel}\left(\mathrm{A}_{1} \mathrm{UA}_{2} \mathrm{U} \ldots . \mathrm{UA}_{\mathrm{n}}\right) \geq \sum_{i}\left[\operatorname{Bel}(A)_{i}\right]-\sum_{i<j}\left[\operatorname{Bel}\left(A_{i} \cap A_{j}\right)\right]+\ldots . . \\
\ldots \ldots+(-1)^{\mathrm{n}+1} \operatorname{Bel}\left(A_{1} \cap A_{2} \cap \ldots . \cap A_{n}\right) \\
4-\operatorname{Bel}(\mathrm{A})+\operatorname{Bel}(\hat{\mathrm{A}}) \leq 1
\end{gathered}
$$

This form of belief function satisfies the Dempster-Shafer belief function axioms[4].

$1-\operatorname{Bel}(\varnothing)=0$

This situation can be easily seen that $\operatorname{Cr}(\varnothing)=0$ and $\operatorname{Pl}(\varnothing)=0$.

$\operatorname{Bel}(\varnothing)=\operatorname{Cr}(\varnothing) * \operatorname{Pl}(\varnothing) \quad$ so $\operatorname{Bel}(\varnothing)=0$

$2-\operatorname{Bel}(\Theta)=1$

Also this equality can be obtained for $\operatorname{Cr}(\Theta)=1, \operatorname{Cr}(\varnothing)=0$ it is easily seen that $\operatorname{Bel}(\Theta)=\operatorname{Cr}(\Theta)[1-\operatorname{Cr}(\varnothing)]=1 *[1-0]=1$

$$
\begin{aligned}
3-\operatorname{Bel}\left(\mathrm{A}_{1} \mathrm{UA}_{2} \mathrm{U} \ldots \mathrm{UA}_{\mathrm{n}}\right) \geq \sum_{i}\left[\operatorname{Bel}(A)_{i}\right]- & \sum_{i<j}\left[\operatorname{Bel}\left(A_{i} \cap A_{j}\right)\right]+\ldots \\
& +(-1)^{\mathrm{n}+1} \operatorname{Bel}\left(A_{1} \cap A_{2} \cap . . \cap A_{n}\right)
\end{aligned}
$$

This inequality can also be seen easily that for every measure of $\operatorname{Cr}\left(\mathrm{A}_{\mathrm{i}}\right) \leq 1$ and $\operatorname{Pl}\left(\mathrm{A}_{\mathrm{i}}\right) \leq 1$ multiplication of $\operatorname{Cr}\left(\mathrm{A}_{\mathrm{i}}\right)^{*} \mathrm{Pl}\left(\mathrm{A}_{\mathrm{i}}\right)$ is much smaller than any one of them. For simplicity, let us take $n=2$ and take a Bayesian credibility function space where $A_{i} \cap A_{j}$ $=0$ for $\forall \mathrm{i} \neq \mathrm{j}$

$\mathrm{Cr}\left(\mathrm{A}_{1} \mathrm{UA}_{2}\right) * \operatorname{Pl}\left(\mathrm{A}_{1} \mathrm{UA}_{2}\right) \geq \operatorname{Cr}\left(\mathrm{A}_{1}\right) * \operatorname{Pl}\left(\mathrm{A}_{1}\right)+\mathrm{Cr}\left(\mathrm{A}_{2}\right) * \operatorname{Pl}\left(\mathrm{A}_{2}\right)-\operatorname{Cr}\left(\mathrm{A}_{1} \cap \mathrm{A}_{2}\right) * \operatorname{Pl}\left(\mathrm{A}_{1} \cap \mathrm{A}_{2}\right)$

In a Bayesian space where $A_{i} \cap A_{j}=0$ for $\forall i \neq j$ it is obvious that

$\operatorname{Cr}\left(\mathrm{A}_{1} \cap \mathrm{A}_{2}\right) * \mathrm{Pl}\left(\mathrm{A}_{1} \cap \mathrm{A}_{2}\right)$ part of this equation will be zero.

$\operatorname{Cr}\left(\mathrm{A}_{1} \mathrm{UA}_{2}\right)=\mathrm{Cr}\left(\mathrm{A}_{1}\right)+\operatorname{Cr}\left(\mathrm{A}_{2}\right)$ and $\mathrm{Pl}\left(\mathrm{A}_{1} \mathrm{UA}_{2}\right)=\operatorname{Pl}\left(\mathrm{A}_{1}\right)+\operatorname{Pl}\left(\mathrm{A}_{2}\right)$.

Consequently, multiplication of the left hand side of these equations will be larger than the right hand side.

$$
4-\operatorname{Bel}(\mathrm{A})+\operatorname{Bel}(\hat{\mathrm{A}}) \leq 1
$$

Since $\operatorname{Cr}(\mathrm{A})+\operatorname{Cr}(\hat{\mathrm{A}}) \leq 1$ and similarly $\operatorname{Bel}(\mathrm{A}) \leq \mathrm{Cr}(\mathrm{A})$ and $\operatorname{Bel}(\hat{\mathrm{A}}) \leq \mathrm{Cr}(\hat{\mathrm{A}})$ it is obvious that

$$
\operatorname{Bel}(\mathrm{A})+\operatorname{Bel}(\hat{\mathrm{A}}) \leq 1
$$

According to this proposition we can rearrange the schema of support functions, credibility functions and belief functions as [4] 


$$
\left\{\begin{array}{l}
\text { Simple } \\
\text { Support } \\
\text { Func }
\end{array}\right\} \subseteq\left\{\begin{array}{l}
\text { separable } \\
\text { support } \\
\text { func }
\end{array}\right\} \subseteq\left\{\begin{array}{l}
\text { support } \\
\text { func }
\end{array}\right\} \subseteq\left\{\begin{array}{l}
\text { Crdbl } \\
\text { func }
\end{array}\right\} \subseteq\left\{\begin{array}{l}
\text { belief } \\
\text { func }
\end{array}\right\}
$$

Figure 3. A general view of proposed belief functions [4]

\section{NUMERICAL EXAMPLE}

Let's assume a weather forecast problem. There are some measurements of temperature, wind, air humidity, etc. which give us an opinion about how the weather will be. Opinions about how the weather will be are rainy (A), cloudy (B) and clear (C). Membership measures of each opinion depending on the measures are given in Table 2.

Table 2. Membership measures of each opinion depending on measures

\begin{tabular}{|c|c|c|c|c|c|c|c|}
\hline & A & B & C & AUB & AUC & BUC & AUBUC \\
\hline Temp & 0,2 & 0,1 & 0,1 & 0,2 & 0,1 & 0,1 & 0,2 \\
\hline Wind & 0,2 & 0,1 & 0,1 & 0,3 & 0,1 & 0,1 & 0,1 \\
\hline Humdty & 0,1 & 0,2 & 0,3 & 0,1 & 0,1 & 0,1 & 0,1 \\
\hline
\end{tabular}

According to the membership values given in Table 2, combined membership is calculated as in Table 3.

Table 3. Combined membership measures of the given event

\begin{tabular}{|c|c|c|c|c|c|c|c|}
\hline & A & B & C & AUB & AUC & BUC & AUBUC \\
\hline Comb. Mem. & 0,348 & 0,312 & 0,222 & 0,068 & 0,023 & 0,023 & 0,004 \\
\hline
\end{tabular}

According to these combined membership values, credibility (belief according to Shafer [1]) and plausibility measures are calculated. Some of the calculations are shown

$$
\begin{aligned}
& \mathrm{Cr}(\mathrm{A})=\mathrm{m}(\mathrm{A})=0,348 \\
& \mathrm{Cr}(\mathrm{A} \text { or } \mathrm{B})=\mathrm{m}(\mathrm{A})+\mathrm{m}(\mathrm{B})+\mathrm{m}(\mathrm{AUB})=0,728 \\
& \mathrm{Pl}(\mathrm{A})=1-\mathrm{m}(\hat{\mathrm{A}}) \\
& \mathrm{Pl}(\mathrm{A})=1-[\mathrm{m}(\mathrm{B})+\mathrm{m}(\mathrm{C})+\mathrm{m}(\mathrm{BUC})] \\
& \mathrm{Pl}(\mathrm{A})=0,443 \\
& \operatorname{Bel}(\mathrm{A})=\operatorname{Cr}(\mathrm{A}) * \operatorname{Pl}(\mathrm{A}) \\
& \operatorname{Bel}(\mathrm{A})=(0,348) *(0,443) \\
& \operatorname{Bel}(\mathrm{A})=0,154 \text { (Rounded) } \\
& \text { Similarly } \operatorname{Bel}(\mathrm{B}) \text { can be found as } 0,127 \text { and } \operatorname{Bel}(\mathrm{C}) \text { as } 0,060 \text {. } \\
& \mathrm{Bel}(\mathrm{A} \text { or } \mathrm{B}) \quad=\mathrm{Pl}(\mathrm{A} \text { or } \mathrm{B}) * \mathrm{Cr}(\mathrm{A} \text { or } \mathrm{B}) \\
& \operatorname{Bel}(A \text { or } B)=[1-m(C)]^{*}[m(A)+m(B)+m(A U B)] \\
& \operatorname{Bel}(\mathrm{A} \text { or } \mathrm{B}) \quad=0,566(\text { Rounded })
\end{aligned}
$$

Similarly, the formula of $\operatorname{Cr}(\mathrm{A}$ or $\mathrm{B})$ above $\mathrm{Bel}(\mathrm{A}$ or $\mathrm{B})$ is defined as 
$\operatorname{Bel}(\mathrm{A}$ or $\mathrm{B}) \quad=\operatorname{Bel}(\mathrm{A})+\operatorname{Bel}(\mathrm{B})+\operatorname{Bel}(\mathrm{AUB})$

Bel(AUB) represents residual belief measure that is not especially allocated to A or B but allocated to "A or B". Substituting the values found above, the value of Bel(AUB) can be calculated.

$$
0,566=0,154+0,127+\operatorname{Bel}(\mathrm{AUB})
$$

$\operatorname{Bel}(\mathrm{AUB})=0.285$

All the computed values are shown in the Table 4.

Table 4. Belief measures of the given event.

\begin{tabular}{|l|c|c|c|c|c|c|l|}
\hline & A & B & C & AUB & AUC & BUC & AUBUC \\
\hline Bel & 0,154 & 0,127 & 0,060 & 0,285 & 0,193 & 0,175 & 0,005 \\
\hline
\end{tabular}

\subsection{A View to a Special Property of the Proposed System}

In a Bayesian probability function space in which $\mathrm{A}_{\mathrm{i}} \cap \mathrm{A}_{\mathrm{j}}=0$ for $\forall \mathrm{i} \neq \mathrm{j}$, probability measures are used as credibility measures; thus, belief functions turn to be square of credibility functions [4].

$$
\begin{aligned}
& \operatorname{Bel}(\mathrm{A})=[1-\operatorname{Cr}(\hat{\mathrm{A}})]^{*} \operatorname{Cr}(\mathrm{A}) \\
& \operatorname{Bel}(\mathrm{A})=\operatorname{Cr}(\mathrm{A})^{*} \operatorname{Cr}(\mathrm{A})
\end{aligned}
$$

According to this arrangement in a head or toss experiment, we can say that probability of head (or toss) is also a credibility measure and it is equal to 0,5 . In Bayesian probability space, measurement of Head $U$ Toss must be equal to zero. After calculating belief measure for head (or toss) it can be easily seen that it is equal to 0,25. Obviously the residual belief measure will be allocated to Head U Toss option.

Table 5. Credibility and belief measures of a Head or Toss game

\begin{tabular}{|c|c|c|c|c|}
\hline & Head & Toss & Head U Toss & Head or Toss \\
\hline Cr & 0,50 & 0,50 & 0,00 & 1 \\
\hline Bel & 0,25 & 0,25 & 0,50 & 1 \\
\hline
\end{tabular}

In this representation

$\mathrm{Cr}($ Head or toss $)=\mathrm{Cr}($ Head $)+\mathrm{Cr}($ Toss $)+\mathrm{Cr}($ Head U toss $)$

$\operatorname{Bel}($ Head or toss $)=\operatorname{Bel}($ Head $)+\operatorname{Bel}($ Toss $)+\operatorname{Bel}($ Head U toss $)$

In this formulation Bel(Head U Toss) can be considered as a reserved belief that is neither allocated to head nor allocated to toss but allocated to "Head or Toss" option. 


\section{CONCLUDING REMARKS}

In this paper, some of the formulations are put forth in a heuristic way. How we think or how we believe is an innate knowledge. We presented a formulation for this knowledge and explained why it is tackled in such a way.

This study aims to get a distinction between credibility and belief. Different ideas about an event are the antitheses of each other. Each idea's credibility is only as valuable as the other thesis left us to take into account. So when calculating belief degree of an idea, we must consider both idea's credibility and complement of this idea's credibility. According to this formulation it can be seen why the inequality below is true

$$
\operatorname{Bel}(A U B) \geq \operatorname{Bel}(A)+\operatorname{Bel}(B)-\operatorname{Bel}(A \cap B)
$$

Such an arrangement is going to be more helpful for making computers think like people, since the people actually think like this formulation. This formulation can be studied further because of its important properties.

\section{REFERENCES}

1. G. Shafer, A Mathematical Theory of Evidence. Princeton University Press, Princeton, 1976.

2. G. J. Klir and T. A. Folger, Fuzzy Sets, Uncertainty and Information. Prentice Hall, 1988.

3. D. Dubois and H. Prade, Possibility Theory. Plenum Press, 118-119 New York, 1988.

4. M. Nebioğlu, Inanç Fonksiyonlarına Getirilen Bir Ayrım ve Senaryo Değerlendirmesinde Uygulanması, Doctoral dissertation, Sakarya University, 2011.

5. M. Nebioğlu, T. Çakar and F. M. Duran, A New Distinction in Belief Functions. 1st International Symposium on Computing in Science \& Engineering 2010 Proceedings. 